\title{
Business School Teaching of Research Methods - A Review of Literature and Initial Data Collection for Undergraduate Business School Students
}

\author{
Anthony Mitchell ${ }^{1}$ and Martin Rich ${ }^{2}$ \\ ${ }^{1}$ Ashridge Executive Education, Hult International Business School \\ ${ }^{2}$ The Business School, City, University of London \\ Anthony.mitchell@ashridge.hult.edu \\ DOI: 10.34190/JBRM.18.2.003
}

\begin{abstract}
This paper reviews approaches to teaching research methods and the effectiveness of the student supervisor relationship in managing research projects. Corporate scandal, changes in society, the emergence of online technologies and a need to reduce teaching costs have all led business schools to change their curriculum including how research methods are taught and undergraduate and postgraduate projects supervised. Management research, and the manner in which research methods are both taught and practiced continue to make a key contribution and play a significant role in the partnership between academia and practice. Virtual learning has been helpful in a better understanding of research methods, developing critical thinking and understanding issues in more depth that are briefly covered in class. Researchers have found that the blending learning approach and use of computer-mediated discourse supported a collaborative learning approach and resulted in more active and reflective learners (Altinay and Paraskevas, 2007). Despite this positive example, the use of technology for learning has generally been limited to supplementing face to face learning (Thomas and Thomas, 2012). The class is increasingly culturally diverse, students more mobile while academics may be Anglo-centric and westernised. Supervision needs to be responsive to the changing needs and ambitions of the student; to move away from a dyadic relationship between supervisor and student, and emphasise the importance of collaborative learning environments and collective models of supervision (Malfroy, 2005). Literature reviewing three related research questions is presented. Questions remain as to whether changes are driven by a need to reduce cost or improve pedagogy. Data collection has started with undergraduate business students through pilot surveys and interviews to gain an improved understanding of the trends, initiatives and best practice. A further paper will explore in more detail postgraduate business students. At a time when some schools are moving more content on-line and seeking new forms of assessment so there is a need to ensure that management research continues to fulfil a contribution towards intellectual and practical understanding. Corona virus has made this need more urgent.
\end{abstract}

Keywords: teaching research methods, curriculm design, use of technology, project supervision

\section{Introduction}

\subsection{Aim}

This paper reviews literature for differing approaches to the teaching of research methods and the effectiveness of the student supervisor relationship in managing research projects. Ideas are then tested with a small group of undergraduates at a London based business school. Data collection surveys and interviews will then be reviewed and used with a wider group of Masters level students in a subsequent paper.

\subsection{Research Questions}

The following questions are explored:

RQ1 How are Business Schools adapting to changing needs and criticism?

RQ2 How does an understanding of research methods contribute to the curriculum?

RQ3 How might the supervisor and student work together more effectively?

Firstly, how are Business Schools adapting to changing needs and criticism?

When the author attended business school as a student in the early 1970's, management was taught in the context of management science with an emphasis on mathematical, statistical and computer-based models. Since then many institutions have regarded the subject of management more as an art and focus on leadership skills. Discussions considering the development and support of managers has ranged from regarding education for those engaged in the "art" of management, to the view of management as an academic discipline following 
the methods and techniques of a "science" (Wilson, 2015). During the early millennium a number of corporate scandals, resulted in a rethink of what should be on the curriculum of MBA or MSc in Management programmes. A seminal paper by Ghoshal (2005) argued that simply 'adding' the teaching of ethics was insufficient and that schools should stop teaching 'bad' management theories that were destroying good management practices. The poor application and misinterpretation of agency theory, transaction costs, shareholder value, incentive payments, competitive advantage and other ideas resulted in a 'roller coaster' approach to what is considered to be good or poor practice. Unlike theories in the sciences it may be the case that in the social sciences liberal and pessimistic assumptions about people and institutions become a self-fulfilling prophecy. Modules in ethics, social responsibility and mindfulness are today commonplace and consistent with management education increasingly regarded as a social science. Similarly, the inclusion of differing approaches to research methods has emerged with more tolerance towards mixed methods and methodologies (Mitchell, 2018). Given substantial shifts in what is considered to be acceptable business behaviour it therefore seems appropriate to briefly review how changes in a workplace environment might influence the manner in which business schools develop programmes and the context in which business schools encourage research initiatives, including student assignments and dissertations.

Reviewing the impact that more recent turbulent times have had on management education, Anderson et al, (2018) argue that business school research is increasingly less relevant to practitioners. Since late 2016 a series of events have been widely addressed both online and in social media through a business and management practice lens. Higher fees together with the impact of league tables have led to consumers of higher education expecting better paid jobs. This may not be the case given an increase in overall graduates and a decline in traditional 'graduate' jobs. Furthermore, Business Schools are not always the cash cow that they once were for universities (FT, 2018). At some schools this has resulting in fewer students and curriculum redesign. The Economist (2019) reports how US business schools are again reinventing the MBA where the typical two-year expensive version needs to compete with short one-year European as well as on-line models. Thus, it is not always clear whether curriculum changes have student needs and pedagogy foremost.

Secondly, how does an understanding of research methods contribute to the curriculum?

With an awareness of so called VUCA (originally a US military phrase now widely used in business - volatility, uncertainty, complexity and ambiguity) why is an ability to conduct research and to be familiar with research methods important for business students? Cassell (2018) argues that many of the skills required to conduct research are also important for managerial effectiveness and that learning research skills has an impact beyond becoming a competent researcher. This is further supported with calls for a return to scientific methods being included in management education stemming from the advocacy of evidence-based management (Graen, 2009). See also 3.0 below. "For managers, the ability to conduct research is seen as a way of accelerating the process of understanding uncertain circumstances that then leads to a better determination of the actions required to create order out of chaos" (Easterby-Smith et al., 2002 cited in Altinay and Paraskevas 2004 p 624).

Thirdly, how might the supervisor and student work together more effectively?

As expected, approaches will vary between schools, programmes and faculty, also at undergraduate and postgraduate level. There is growing evidence of a move away from a dyadic relationship to one based more upon a collaborative and collective model. There are a number of factors - a need to improve completion rates, concern over consistency in approach, skills and the role. Also, an increase in virtual tuition is a consideration Gurr (2001), Malfroy (2005), Mainhard (2009)) and Corner (2017) (see 5.0 below) as is the extent to which a research student is expected to follow and mirror the footsteps of their supervisor.

In summary, the challenge for Business Schools is to offer a balanced education encouraging students to '...figure things out, adjust to events as they unfold, act in ways that will serve their own economic interests, and contribute to their companies, their communities, and their countries" (Wilson, 2015). Teaching of research methods is therefore central to preparing business students to meet this challenge. To get the full value from research the student-supervisor relationship is critical.

The following themes will be explored in more depth: business school teaching of research methods, the role played by technology and the effectiveness of student-supervisor relationships. 


\section{Literature Review}

\subsection{Business School teaching of Research Methods}

The teaching of research methods is a part of the curriculum in most schools. There is a growing concern for achieving 'impact' research (yielding benefits beyond academia that influence society, culture, our environment and the economy (Bornmann, 2012)) such that an appropriate choice of method for student assignments and a dissertation reinforces the importance of a keen grasp of research methods. There is a gap between what academics are interested in researching and what practitioners may consider to be important. Arguably, best practice is underpinned and supported by both academic theory and evidence. Two papers by Rousseau (2006) and Rousseau and McCarthy (2007) argue that research methods teaching reinforces the notion that Business Schools should learn from medicine by practicing evidence-based research and method. Three premises for this are offered. Firstly, that science-based practice promotes better decisions, improved outcomes and greater success with implementation. Secondly, personal development leads to a career based on frequent, replicable learning; and thirdly, collaboration builds closer ties between educators, scholars and practitioners. For doctoral students, research methods training is crucial to the development of the management discipline, yet acquiring depth and breadth across research methods education in a doctoral program can be challenging (Madden et al, 2016).

\subsubsection{Content and curriculum}

Aguinis et al, (2009) conducted a content analysis of 193 articles published in the first 10 volumes (1998 to 2007) of Organizational Research Methods (ORM). The most popular quantitative topics include surveys, validity, reliability, regression/correlation and multilevel data analysis. The most popular qualitative topics are interpretive, policy capturing, and action research surveys and reliability; interpretive, policy capturing, and content analysis. A case study (Dong, 2018) presents a case where the tutor used grounded theory methods (GTM) to teach postgraduate students. The whole teaching and learning process is made into a piece of research done by the students using GTM. Flipped classroom approach is used to transform the students into researchers. Dong addresses epistemology and ontology aspects of GTM, coding and theory building and other characteristics of GTM in designing the teaching and learning activities. An initial evaluation survey indicates a positive outcome but this will need to be validated by further evaluation and any possible modifications to the course design. Stirling Business School reviewed management education concluding that graduates should be prepared for chaotic and demanding business environments, undertaking different careers in multiple organisations over the 50 years of a typical working life. A balance needs to be regained between imagination, creativity, critical thinking and the communication of complexity, the acquisition of management techniques and a knowledge of the breadth and context in which we are now expected to operate (Wilson, 2015). Such transitions impact on our work environment suggesting that research might focus upon adaptive, reflexive approaches that support flexibility, deploying scenario planning and appropriate forms of experiential learning rather than outdated strategic management frameworks. Developing the notion of the student perspective on the purpose of business school teaching, Koris et al (2017) suggest that undergraduate students in Estonia, Austria and Germany expect a balanced education; not just to replace existing, successful managers but also to increase oganisational effectiveness while being humane, ethical, eco-friendly and able to promote social welfare and justice. Knowledge ought not to be offered as truth. Encouragement needs to be given to both critical thinking and the adoption and appreciation of differing perspectives.

\subsubsection{Style of delivery and review}

Many institutions acknowledge that students find courses in research methods challenging. Edwards and Thatcher (2004) question whether a traditional didactic teaching approach facilitated student learning, optimized student achievement or adequately prepared students for their dissertation; and ought to be replaced with a student-centred, tutor-led approach. Humphreys (2006) reviewed his practice of joint teaching of research methods to large postgraduate groups and proposed that there is value from self-reflexivity to the teacher by looking 'inward' at personal learning experiences. This is particularly so when reviewing difficult and complex situations that may be the richest sources of empathy and insight. A research methods course that requires compulsory student completion of a commissioned project has been successfully deployed for five years. Student evaluations highlighted positive learning benefits. 89 studies in higher education generated several common themes (Earley, 2014): student characteristics, teaching methods, and the course content and goals. Some gaps identified included the assessment process and insights on how students learn on research methods courses. A flipped classroom becomes more effective when it involves rethinking assignments (Tucker, 
2012). Course redesign can incorporate more active learning and real-world assignments, rather than accumulating knowledge as is often done in traditional qualitative courses, the exemplar showed that by "flipping" the assignments with a focus on outcomes and skill application, student learning and satisfaction increased.

Worcester Business school (Bell, 2016) has adopted a new teaching approach focused on independent learning designed to combine the advantages of an intensive module format (from weekly over a twelve-week module to a concentrated two-week design) with increased student engagement through participation in topic themed groups. The new format was designed to help students increase their understanding of the subject matter and its applicability to their research; and ultimately, to improve grades in assignments as well as in research methods courses. Students received feedback after each stage of the process by interacting regularly with their groups and faculty. The outcome of the change in course format was measured by a quantitative analysis of the grades achieved from two assessments, which were compared to grades from the previous year's courses. In conclusion, the change in format resulted in improved assessment scores and a greater ability of students to apply their learning to research projects. External review also testifies to the success of the approach, which has been commended by external examiners and the QAA review team during their subject review.

Rich (2014) suggests that recent discussion in higher education has focused on providing personal learning. This influences a range of factors, expectations of the learning environment, styles and methods used by lecturers, the need to deliver specialist material to students, and the technological infrastructure adopted to support learning. Electronic resources to support learning could be delivered through a 'personal learning environment', as distinct from a 'virtual learning environment', the implication being that personalisation is a core component. For teaching research methods, a personalised approach is attractive because students can be expected to vary in what research approaches they are likely to use in their studies and will make choices about what research methods they choose to learn. In a later study, at City's Business School in the UK, Rich et al, (2019) explore a Problem Based Learning (PBL) approach to the teaching and application of research methods at undergraduate level.

\subsection{The Role of Technology}

The Covid-19 outbreak in 2020 has led many institutions to replace classroom teaching with variants of on-line learning. Some business schools already offered this method as a delivery channel and others have various 'blended' solutions offering a mix of classroom and on-line learning. Whether these changes will be temporary for some remains to be seen. It appears likely however, that use of various technologies are now here to stay and represent a major change both for faculty teaching and students learning at university. Let us now review some of the recent technological innovations:

\subsubsection{MOOC}

In recent years massive open online courses (MOOCS) have been developed and popularised by US business schools. At SOAS in the UK the 'Understanding Research Methods' MOOC (Lee and Rofe, 2016) has achieved good results and offers lessons for further consideration. During the first iteration managing the forums was a key to success in providing a well-facilitated site of learning and helps to counter scepticism regarding whether MOOCs facilitate meaningful learning. More importantly, it challenges a common view of assessment, where student engagement in online learning environments is evaluated through frequency of posts on forums and student learning is assessed by the quality of one final written assignment. Given the international composition of student cohorts and greater availability of data, MOOCs and other such open courses are ideal for studying students' peer learning and monitoring their iterative and incremental development.

\subsubsection{Innovation enabled by technology}

Developments in technology have also enabled more innovation and flexibility in research methods education. The management education and research sphere has been criticised for a lack of methodological diversity, Madden et al (2016) present the Consortium for the Advancement of Research Methods and Analysis (CARMA provides expertise on research methodologies from basic to advanced level in areas from epistemology to statistical data analysis. Learning is by online webcasts. see 3.0 above) and argue this could be part of a move towards improving the diversity of research skills and approaches taught in business and management schools. Technology and the internet have not only diversified the range of research methods education available, but also provided options in terms of the format and delivery of the educational content. Students research work is often of a personalised nature, given that students are required to design their own enquiries, methods and 
answer questions that are relevant to their studies but also of interest to them. As a result, Rich (2004) asks whether student's training into research methods should be equally personalised to match (see 3.3 above). Personalisation can refer to alternate paths for students to take depending on their knowledge level or ability. It may also include the availability of content in different formats depending on the students' learning style. Rich (2004) concludes that personalised learning broadens the possibilities for research training, however, there are some important considerations. Primarily, universities must ensure that they have sufficient electronic resources to enable successful personalised learning. Supervisors and tutor roles in students learning are crucial, yet the introduction of personalised learning changes this role in that the supervisor may not necessarily continue to be the most important source of guidance, instead supervisors must be prepared to act as 'brokers' of content in a personalised learning context (see also 5.0 below).

Altinay and Paraskevas (2007) evaluated the use of computer-supported collaborative learning approach and investigated whether this approach resulted in 'higher order thinking' during a research methods course taking a blended learning approach. Alongside face to face lectures students engaged with a virtual learning environment which involved the use of the internet to obtain information, students took self-testing quizzes to assess understanding and were asked to contribute to an asynchronous computer-mediated discourse in the form of a discussion board. Results showed that students found the virtual learning helpful in understanding new concepts, developing critical thinking and understanding issues in more depth that were only briefly covered in class. Researchers concluded that the blending learning approach and use of computer-mediated discourse supported a collaborative learning approach and resulted in more active and reflective learners. Despite this positive example, the use of technology for learning has generally been limited to supplementing face to face learning perceived to be of a higher quality (Thomas and Thomas 2012). This raises the question whether students perceive on-line learning as a cost saving by the institution, or worse as second best in terms of delivery style. Many university campuses will need to rethink the space available for flexible study, also the provision of IT systems and networks. It may be that too much space is deicated to tradional lecture rooms and libraries (Remenyi, 2019).

\subsection{Student-Supervisor Relationship}

\subsubsection{Consider culture}

Franke and Arvidsson (2011) identified two approaches to supervision through interviews with supervisors in Sweden, namely, research practice-oriented supervision and research relation-oriented supervision. While the former centres on student and supervisor sharing a common research practice, the latter is not based on this common ground, and is instead bound by the supervisor's interest in the students learning process and development. Researchers conclude that a combination of approaches is probably beneficial, ultimately however, they encourage supervisors to develop an awareness of these and other approaches to create positive and beneficial doctoral experiences. Corner et al (2017) focused specifically on the supervision of international students in a management school setting. They note a number of tensions that effect the relationship and ultimately the success of research degree offerings, namely, the difference in writing conventions and the implicit and unconscious assumptions supervisors hold about students. Corner argues that the community of management academics exist as a 'club', with its own assumptions and worldviews that are principally Anglocentric and westernised. They question how international students without this native stance can survive in an academic world that is not designed for them, with supervisors who are unable to support them and address these unconscious tensions. The authors suggest that the growing body of international business students pursuing research degrees or research courses presents an opportunity to develop an assessment tool to determine how successful these supervisory relationships are. Similarly, Wang et al (2011) focuses on the feedback practices between supervisors and their international students. Through interviews with international doctoral students they too acknowledge a difference in writing and interpersonal communication styles between student and supervisor.

\subsubsection{Supervisory skills}

Through a reflection on existing literature, Pearson and Brew (2002) conceptualise a supervisor development programme in response to some of the emerging challenges of research methods teaching. They argue that the increasing demands on research programmes are narrowing the process down to competency-based, generic skills training to ensure employability after, rather than the production of unique contributions to knowledge. Ultimately, Pearson and Brew suggest that to adapt to this new model, supervisors must 'expand their repertoire of skills as educators and leaders' (pg. 143), they argue that being limited to one model of supervision is no 
longer acceptable. In line with others, they propose that supervision needs to be responsive to the changing needs and ambitions of the student, and therefore supervisors must learn to be adaptable. Kam (1997) reached similar conclusions in the 90's after conducting a survey of 250 research students, focusing explicitly on a student's dependency on their supervisor. Ultimately, she acknowledged that a prescriptive supervisory model was not appropriate given the changeable characteristics of students, practice, role and expectation. Research by Lee et al (2008) showed that supervisors of management studies identified with the full range of categories including, functional, enculturation, critical thinking, emancipation and relationship development. Recognizing the importance of a positive relationship Howells et al (2016) focused attention on how this relationship is enhanced. Their qualitative study of supervisors and their PhD students suggest that the practice of gratitude has a positive impact on communication, social and emotional wellbeing and crucially on the research process by aligning expectations of both parties. Faculty are increasingly expected to contribute and add value across the institution, not just to their specialised subject area.this will require the acquisition of additional skills (Remenyi,2019).

\subsubsection{Matching the student with the supervisor}

The Supervisor / Student Alignment Model (Gurr et al 2001) was trialled on PhD students and supervisors, with participants suggesting it went some way towards managing challenges, developing the students' independence and allowing for a dynamic relationship. Malfroy (2005) conducted an ethnographic study to investigate doctoral education in two Australian universities. She suggests that doctoral education needs to move away from conceptualisations based on a dyadic relationship between supervisor and student, and instead emphasise the importance of collaborative learning environment and collective models of supervision. Similarly, Burnett (1999) argued for the benefits of moving towards a collaborative cohort model to increase completion rates among doctoral students. By having a collective of fellow students and experienced mentors, students were able to overcome some of the challenges associated with poor supervision or difficult interpersonal relationships. Despite these suggestions, the dyadic supervisory model remains across most UK universities. There is a more recent UK trend for doctoral candidates to have two rather than one supervisor. This has several benefits, the candidate has some protection if the lead supervisor leaves the university, it also helps develop new doctoral supervisors and the candidate may also experience the richness of a diversity of views although that may come with the risk of confusion!

To synthesise, the literature reviewed suggests that the following three themes emerge:

The need to enhance critical thinking skills is important, perhaps even more so at an undergraduate level; options should be explored on improving the phasing and timing of research methods teaching; virtual learning, personalised learning and problem based learning all of which offer attractive alternatives to large class, conventional teaching of research methods.

Technology has enabled, and arguably accelerated the rate of change and development in how faculty teach, present content and work with both individuals and groups of students to facilitate and engage students in their learning. This presents a further challenge for faculty in setting a curriculum that both covers the syllabus and leaves scope for personalised learning. At the time of writing a challenge for many UK universities is an overreliance on international students who pay higher fees. If the delivery is to be 100 per cent on-line then fee structures may need review, there may also be a threat to the survival of those institutions with a lower ranking or who are lacking in brand and reputation. The growing availability of top Instutional MOOCs also places pressure on the quality of materials and fee structures.

As diversity increases an Anglo-centric approach to student-supervisor relationships and project management may not be desirable. There is a clear argument not to just expect faculty to be able to supervise student project work but to ensure that that supervisors are briefed on the project guidelines, are familiar with the research methods training given to the students and have the necessary skills and emotional intelligence to perform the role. The relationship need not just be on a 1:1 basis, a group approach and access to other supporting faculty is often desirable.

\section{Methodology}

Early in 2020 final year undergraduates were starting to prepare for their project dissertations which were due to be submitted in April. The academic year for these students was structured around exams in January and in May so students were encouraged to put effort into their dissertations as soon as the January exam period was complete. These undergraduates were enrolled in Business Management degrees at a time of transition to a 
new degree structure including redesigned approach to the teaching of research methods (Rich, M. Brown, A. and Banerjee A. 2019). Semi-structured surveys with a range of questions in open free format, closed and Likert scale format exploring the above research questions (2.2), were posed at City's Business School in London. (An example of the student survey is included as an appendix (9.) The timing has been influenced by Covid-19 and so while starting with surveys of business undergraduates and faculty interviews the sample is smaller than hoped for. A small number of recent alumni were also surveyed and additionally the views of alumni expressed at a panel convened by the university's careers service was used as a focus group. Faculty and Masters students will be addressed at a later stage with redesigned questions based on this pilot experience, and will be the subject of a separate paper. Surveys were sent to faculty, which mirrored the questions in the student survey, and semi-structured interviews were carried out with faculty members to supplement these.

\title{
4. Data Collection
}

Three parallel questionnaires were initially set up using Qualtrics online survey software, one for students, one for academic staff who were supervising students' dissertations, and one for academic staff with responsibilities as course director or associate dean which covered overall design of the undergraduate courses. These were distributed in early February 2020 using an email containing a link and explaining the background. Additionally the associate dean for education, and two lecturers with considerable experience of project supervision, were identified as interview subjects. The two supervisors interviewed were selected as two academics who had in common that they took on a considerable amount of supervision responsibility, but who worked in contrasting disciplines within the Business School and who had very different academic backgrounds. Subsequently, in April 2020, a fourth similar questionnaire was distributed to alumni who had participated in an event held for current students.

Table 1: Summary of initial interviews

Summary of initial interviews (2 senior lecturers, 1 Assoc. Dean, 1 Course Director)

\begin{abstract}
Trends
Cass have enjoyed substantial recent growth in undergraduates resulting in changes to teaching method, structure and syllabus. Technology developments have enabled blended learning and the use of a Moodle platform. A range of specialisms have become a USP and in some cases offer alternatives to projects.

Teaching and curriculum design

Important to have research methods training at $\mathrm{U} / \mathrm{G}$ and $\mathrm{P} / \mathrm{G}$ level. Recognize the importance of critical thinking, use of small groups, ability to question and evaluate own research, development of agile and related competences.

Supervision

Tend to meet monthly over a three month period. Some faculty not keen on supervision, there is a need for students to be challenged. There is considerable autonomy.
\end{abstract}

Characteristics

\author{
Good projects \\ Motivated, engaged with the subject \\ Close to career goals \\ Focus on secondary data at U/G level \\ Insights and understanding of issues
}

\author{
Poor projects \\ Little idea what to do / of interest \\ Poor primary data collection / little idea how to analyse \\ Family based projects - ethical issues and poor data availability \\ Over focus on practicality ignore academic content \\ A business report or budget rather than an academic dissertation
}

While the initial circulation of the questionnaire took place before the Covid-19 pandemic had a major influence on the life of the university, by the time that it would have been appropriate to follow students up, they were preoccupied with the pandemic and in many cases, these being final year students, concerned that they might be unable to complete their degrees on time.

The first interview, with the associate dean for education, was conducted face-to-face. The two subsequent interviews with project supervisors were conducted over Zoom while the university buildings were closed due to the pandemic. From the beginning of March 2020 significant numbers of students made arrangements to stop attending the university in person, even though at the time the official advice from the British government was that teaching should go ahead as planned. Some students from outside the UK returned to their home countries expressing concern that international travel might become difficult or impossible, and that if they did 
not return at that point they might be separated from their families indefinitely. The Business School switched all formal teaching to take place online in mid-March 2020 and for the May exam period, conventional invigilated exams were replaced by assessments which could be completed at home over a 24 hour period. Final year students were nevertheless expected to complete their projects during April, albeit with the due date for handing these in postponed by two weeks from that originally set and with a much more sympathetic attitude to requests for individual extensions to the deadine than would normally apply.

In these conditions it proved impossible to obtain more responses from students beyond those who had completed the survey when it was first released, and difficult to encourage teaching staff who were typically preoccupied with rapidly putting together online material to provide input. Both students and academic staff found themselves confronted with new challenges around dissertation supervision, for example students suddenly finding themselves with limited access to people who were to provide them with data and with no opportunity to visit the university library in person. Although some of these highlighted issues which already affected the supervision process it would have been difficult to elicit objective responses from either students or staff which focused on the teaching of research methods as a whole, and not on the immediate response to the pandemic.

Responses from a number of project supervisors did raise some interesting points about the structure and coverage of the questionnaires, which could potentially inform the questionnaire design for subsequent research covering different cohorts of students. These supervisors were all supportive of this research and stressed that any criticism of the original questionnaire was intended constructively. They highlighted a disconnect between the sections of the questionnaire relating to the three research questions, notably that respondents who were comfortable answering questions on the supervision process, and had a lot to say in free text comments on this, were reluctant to answer questions on the teaching of research methods as a whole simply because their exposure to teaching research, at least on the Business School's undergraduate courses, did not extend beyond their responsibilities as supervisors.

\section{Initial Findings - undergraduate business students}

\subsection{Responses from Students}

Table 2: Summary from undergrraduate student survey data

Summary from Undergraduate student survey data Initial sample 12 students

\begin{tabular}{|l|l|}
\hline Teaching Research Methods & \multicolumn{1}{|c|}{ Student - supervisor relationships } \\
\hline $\begin{array}{l}\text { Mixed views on whether the teaching of RM is predominantly blended, online or } \\
\text { classroom based }\end{array}$ & Agreement that there is a process to resolve difficulties if required. \\
\hline Mixed opinions on teaching of RM & No agreement on whether a prescribed approach is followed. \\
\hline $\begin{array}{l}\text { Strong agreement that an understanding of RM is applicable to both U/G and P/G } \\
\text { students }\end{array}$ & Agreement that students can influence choice of supervisor. \\
\hline $\begin{array}{l}\text { Most agree that upon graduation an understanding of RM is beneficial to career } \\
\text { prospects. }\end{array}$ & $\begin{array}{l}\text { Mixed views on 1:1 or group working, also on consulting with other faculty } \\
\text { members. }\end{array}$ \\
\hline Mixed views on whether there is a prescribed approach at CASS to RM. & Mixed views on involvement of employer \\
\hline $\begin{array}{l}\text { General agreement that understanding of RM is an essential skill set, also that } \\
\text { there is an appropriate assessment in place. }\end{array}$ & 'somewhat 'agreement on guidance from the supervisor on RM \\
\hline Mixed views on whether students can choose from a range of project types. & Varied opinions on frequency of meeting \\
\hline No awareness of future curriculum / design changes in this area. & $\begin{array}{l}\text { Consistent agreement on the importance of written and verbal feedback } \\
\text { improvement }\end{array}$ \\
\hline & \\
\hline
\end{tabular}

\begin{tabular}{|l|l|}
\hline \multicolumn{2}{|c|}{ Synthesis } \\
\hline $\begin{array}{l}\text { General agreement that RM is an essential skill / competence and that there should } \\
\text { be career benefits after graduation. } \\
\text { Mixed views on teaching method, whether or not there is a prescribed approach and } \\
\text { on the choice of differing project type }\end{array}$ & $\begin{array}{l}\text { Consistent agreement on the value of both verbal and written feedback, the } \\
\text { opportunity to influence choice of supervisor, also that there is a process for } \\
\text { resolution if difficulties are experienced. } \\
\text { A suggestion that more structure and clarity around 'what is expected' would be } \\
\text { beneficial. }\end{array}$ \\
\hline
\end{tabular}




\section{Would students expect there to be benefits post course completion from an appreciation of research methods e.g. career benefits?}

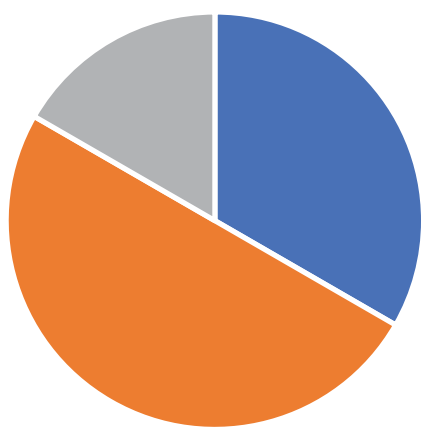

- Strongly agree - Somewhat agree $\quad$ - Neither agree nor disagree

Figure 1: Would students expect there to be benefits post course completion from an appreciation of research methods e.g. career benefits?

Does the course have a prescribed or preferred approach to research method e.g. action research, qualitative or quantitative methods?

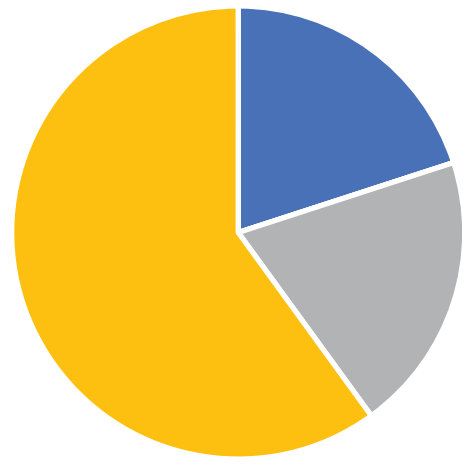

- Strongly agree $\quad$ Somewhat agree $\quad$ Neither agree nor disagree $\quad$ Somewhat disagree

Figure 2: Does the course have a prescribed or preferred approach to research method e.g. action research, qualitative or quantitative methods?

\subsection{Responses from Supervisors}

12 academics who supervised undergraduate dissertations completed questionnaires. Most of them expressed limited knowledge about what teaching of research methods took place in advance of, or in parallel with, the dissertation and some expressed concern that students had been insufficiently prepared to carry out individual research. An example from the discursive comments from supervisors was 'students are expected to run their own research projects... but they lack the skills (methods-wise, but also for writing a literature review) to do so'. Another supervisor, asked about the subject's place within the course as a whole, simply remarked that 'some students merely ignore [research methods]'. Another observed that 'they are confused about many aspects of the process, especially ethics approval'. One significant change that took place during this cohort's time at university was the introduction of an online system for ethics approval across the university, driven by institutional policy and external factors and not by any pedagogic considerations. It is telling that the foremost area of confusion identified in this case was a around a practical issue and not around deeper understanding of research.

Given the lack of awareness of the teaching process, it is unsurprising that there were differences in responses to other points. For instance in response to the question 'How much are employers involved in identifying and 
supporting student projects?' most supervisors suggested little or no involvement, but one highlighted particular initiatives affecting a small number of innovative projects. Supervisors had different perceptions of how much teaching of research methods was delivered online and how much face-to-face, typically suggesting that in practice they simply were not aware of the answer. On the question of whether there was a preferred approach to research methods, covered by one of the Likert scale questions, there was no consensus with half of the respondents neutral on this point:

Table 3: Summary supervisory survey data

Summary Supervisory survey data Initial sample 12 supervisors

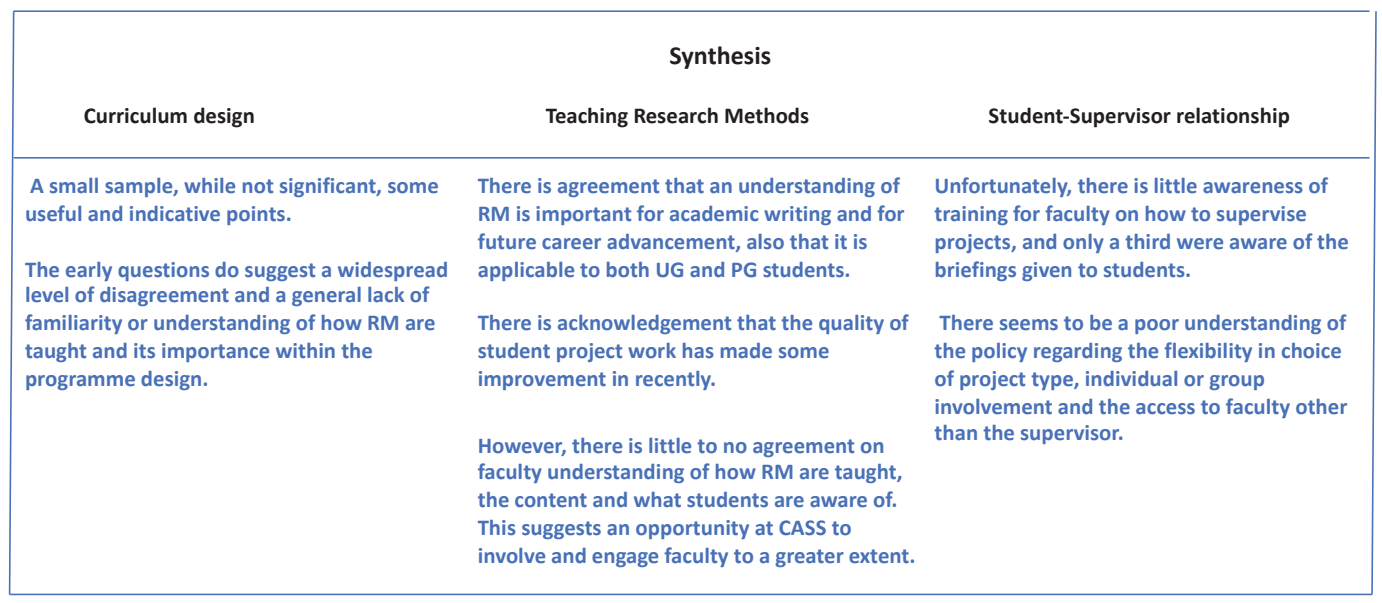

Does the course have a prescribed or preferred approach to research methods?

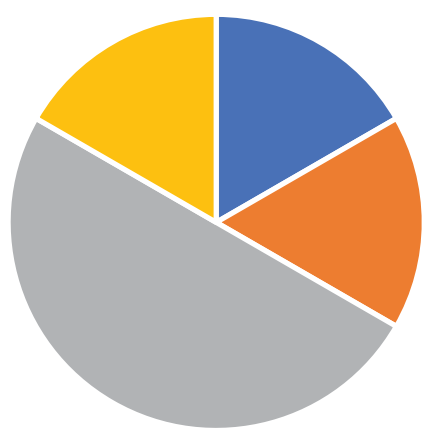

$$
\begin{aligned}
& \text { - Strongly agree } \quad \text { Somewhat agree } \quad \text { Neutral } \\
& \text { - Somewhat disagree } \text { - Strongly disagree }
\end{aligned}
$$

Figure 3: Does the course have a prescribed or preferred approach to research methods?

A very similar pattern was seen in supervisors' perceptions of whether projects had improved over the past few years: 


\section{Have improvements in the standards of projects been noted in the last three years?}

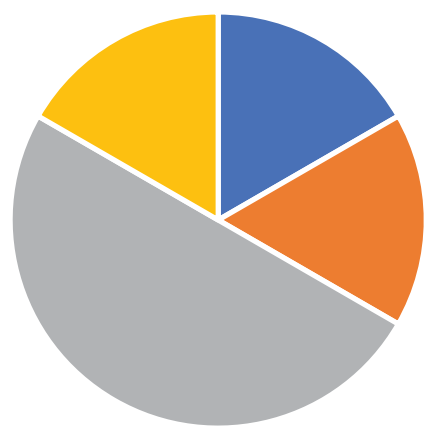

- Strongly agree - Somewhat agree $\quad$ Neutral

- Somewhat disagree - Strongly disagree

Figure 4: Have improvements in the standards of projects been noted in the last three years?

The existence of a range of different types of project which different demands on both students and supervisors raised a number of issues. One of the Likert-scale questions to supevisors set out to determine how much this variety was taken into account in setting up the supervision process. Respondents appeared reluctant either to agree or to disagree strongly with this statement but a majority placed themselves as 'somewhat agree'

Are different learning objectives, content guidelines, and assessment criteria applied to different types of project?

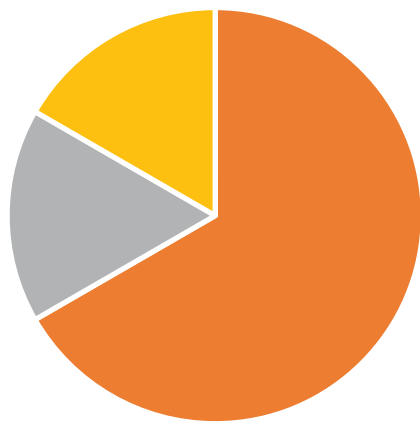

- Strongly agree $\quad$ Somewhat agree $\quad$ Neutral

- Somewhat disagree - Strongly disagree

Figure 5: Are different learning objectives, content guidelines, and assessment criteria applied to different types of project?

\subsection{Responses from Alumni}

Only two alumni, both from within the last five years, responded to the survey. Both reported different, though not inconsistent, memories of learning research methods. One could not remember the extent of the use of online learning for research methods while the other did mention the use of the Moodle virtual learning environment. Both reported that an element of teaching research methods ran through their studies, but it culminated with the final year project. One of them stated '[research methods] formed a core part of the dissertation/final year project but it wasn't focused on much beyond the Systems Thinking and Action Research module studied in our first year'

Both alumni were positive about the importance of research methods to their subsequent careers and its centrality to a business management degree. 


\section{Concluding Remarks}

Business Schools have evolved over the past 50 years as social, economic and related pressures at work have demanded changes to the syllabus and the teaching approach. Management research, and the manner in which research methods are taught and practiced continues to make a key contribution and play a significant role in the partnership between academia and practice.

Specifically, the initial literature evidence suggests:

Business Schools have adapted their curriculum (RQ1) in response to changing needs, greater competition and a need for differentiation. Personal, blended and collaborative learning, a greater awareness of risk, critical thinking, change and socio-environmental issues are today more widespread along with a renewed interest in scenario planning, flipped classroom and live cases (2.2,3.2). We are not clear though of the extent to which changes are driven by cost pressures rather than pedagogy.

An understanding of research methods (RQ2) is important not just for business school students but also for subsequent careers, where ability to conduct research should lead to better decisions to create 'order out of chaos' (Easterby-Smith et al., 2002). There is evidence that the teaching of research methods is better undertaken in custom groups and short intensive tailored modules than traditional semester wide courses for all. (See 2.2, 3.2); also, with the aid of technology (4.0) either in a virtual or blended capacity.

Tensions and dissatisfaction with inconsistent supervisor-student relationships (RQ3) can impact the final result of research. This may be exacerbated by cultural misunderstanding of the role as classroom diversity increases. Supervision is also often perceived as a separate endeavour from the teaching of research methods as a whole, which adds to the scope for inconsistency of approach. There is a trend to move away from a one to one arrangement in favour of collaborative and collective models (5.0).

\section{References}

Aguinis, H., Pierce, C. A., Bosco, F. A., \& Muslin, I. S. (2009). First decade of Organizational Research Methods: Trends in design, measurement, and data-analysis topics. Organizational Research Methods, 12(1), 69-1

Altinay, L., \& Paraskevas, A. (2007). A computer-supported collaborative learning (cscl) approach in teaching research methods. International Journal of Hospitality Management, 26(3), pp. 623-644.

Anderson, L., Hibbert, P., Mason, K., and Rivers, C. (2018). Management Education in Turbulent Times Journal of Management Education, Vol. 42(4) pp. 423-440. Sage.

Bell, R. (2016). The continuing search to find a more effective and less intimidating way to teach research methods in higher education. Innovations in Education and Teaching International, Vol. 53, No. 3, pp. 285-295.

Bornmann, L. (2012) What is societal impact of research and how can it be assessed? a literature survey, Journal of the American Society for Information Science and Technology, Advances in Information Science, Vol. 64, Iss.2

Burnett, P. C. (1999). The supervision of doctoral dissertations using a collaborative cohort model. Counselor education and supervision, 39(1), pp. 46-52.

Cassell, C, Bishop, V, Symon, G, Johnson, P \& Buehring, A 2009, 'Learning to be a qualitative management researcher', Management Learning, vol. 40, no. 5, pp. 513-533.

Cassell, C (2018) "Pushed beyond my comfort zone": MBA student experiences of conducting qualitative research. Academy of Management Learning and Education, 17 (2).

Corner, P. D., \& Pio, E. (2017). Supervising International Students' Theses and Dissertations. Academy of Management Learning \& Education, 16(1), pp. 23-38.

Dong, M. (2018). Teaching a Research Method by Using the Method: The Case of Grounded Theory Method. In European Conference on Research Methodology for Business and Management Studies (pp. 86-94). Academic Conferences International Limited.

Earley, M. A. (2014). A synthesis of the literature on research methods education. Teaching in Higher Education, 19(3), pp. 242-253.

Easterby-Smith, M., Thorpe, R., \& Lowe, A. (2002). Management research: An introduction. London: Sage Publications.

Edwards, D.F. and Thatcher, J. (2004), "A student-centred tutor-led approach to teaching research methods", Journal of Further and Higher Education, Vol. 28 No. 2, pp. 195-206.

Franke, A., \& Arvidsson, B. (2011). Research supervisors' different ways of experiencing supervision of doctoral students. Studies in Higher Education, 36(1), pp. 7-19.

Ghoshal, S. (2005). Bad Management Theories Are Destroying Good Management Practices: Management Education in Turbulent Times, Journal of Management Education, Vol. 42(4) 423-440 Sage

Graen, G. B. 2009. Educating new management specialists from an evidence-based perspective: a proposal. Academy of Management Learning and Education, 8(9): pp. 255-258. 
Gurr, G. M. (2001). Negotiating the" Rackety Bridge"-a dynamic model for aligning supervisory style with research student development. Higher Education Research \& Development, 20(1), pp. 81-92.

Howells, K., Stafford, K., Guijt, R., \& Breadmore, M. (2016). The role of gratitude in enhancing the relationship between doctoral research students and their supervisors. Teaching in Higher Education, 22(6), pp. 621-638.

Humphreys, M. (2006). Teaching qualitative research methods: I'm beginning to see the light. Qualitative Research in Organizations and Management: An International Journal, 1(3), pp. 173-188.

Kam, B. H. (1997). Style and quality in research supervision: the supervisor dependency factor. Higher Education, 34(1), pp. 81-103.

Koris, R., Örtenblad, A., Ojala, T. (2017). From maintaining the status quo to promoting free thinking and inquiry: Business students' perspective on the purpose of business school teaching. Management Learning, Vol. 48(2) pp. 174-186, Sage

Lee, A. (2008). How are doctoral students supervised? Concepts of doctoral research supervision. Studies in Higher Education, 33(3), pp. 267-281.

Lee, $\mathrm{Y}$ and Rofe, s. (2016) Paragogy and flipped assessment: experience of designing and running a MOOC on research methods. Open Learning: The journal of Open, Distance and e-Learning Vol 31, Issue 2

Madden, T.M., Madden, L. Rousseau, M.B., Woehr, D. (2016). Developing depth and breadth of research methods training for doctoral students with CARMA webcasts. The International Journal of Management Education. Vol.14.Iss.3

Mainhard, T., Van Der Rijst, R., Van Tartwijk, J., \& Wubbels, T. (2009). A model for the supervisor-doctoral student relationship. Higher education, 58(3), pp. 359-373.

Malfroy, J. (2005). Doctoral supervision, workplace research and changing pedagogic practices. Higher Education Research \& Development, 24(2), pp. 165-178.

Mitchell, A. (2018). A Review of Mixed Methods, Pragmatism and Abduction Techniques, e journal of business research methods, volume16-issue3-article 492 https://issuu.com/academic-conferences.org

Moules, J (2018) UK universities use business schools as cash cows. Financial Times April 25.

Pearson, M., \& Brew, A. (2002). Research training and supervision development. Studies in Higher education, 27(2), pp. $135-150$

Remenyi, D., Grant, K.A. and Singh, S. (Editors 2019). The University of the Future. ACPI Reading.

Rich, M.G. (2014). Learning Research Methods: How Personalised Should we be? Electronic Journal of Business Research Methods, 12(2), pp. 131-138.

Rich, M., Brown, A. and Banerjee A. (2019). Addressing the challenge of building research capabilities in Business Management Undergraduate students. Electronic Journal of Business Research Methods, 3

Rousseau, D.M. (2006), "Is there such a thing as 'evidence-based management'?", Academy of Management Review, Vol. 31 No. 2, pp. 256-269.

Rousseau, D.M. and McCarthy, S. (2007), "Educating managers from an evidence-based perspective", Academy of Management Learning and Education, Vol. 6 No. 1, pp. 84-101.

Thomas, M. \& Thomas, H. 2012. Using new social media and Web 2.0 technologies in business school teaching and learning, Journal of Management Development. 31(4), 358 - 367

Tucker, C. (2012). Flipped classroom: Beyond the videos [Web log post]. Retrieved from http://catlintucker.com/2012/04/flipped-classroom-beyond-the-videos/

The Economist (2019), Management Education: The next business revolution, November 2nd

Wang, T., \& Li, L. Y. (2011). 'Tell me what to do v guide me through it': Feedback experiences of international doctoral students. Active Learning in Higher Education, 12(2), pp. 101-112.

Wilson., R.G, (2015). The Loss of Balance Between the Art and Science of Management: Observations on the British Experience of Education for Management in the 20th Century. journal of Management Education, Vol. 39(1), pp. 1635 , Sage 


\section{Appendix}

Example of Survey design for research - Student

Introduction

Course

Name (optional)

- The purpose of this survey is to understand the changes and approach taken to the teaching and application of research methods in business schools, and the manner in which supervision is undertaken.

- The results will be treated as confidential and used in preparing an academic paper.

- Your name is required only if you are willing to participate in follow-up interviews, you will remain anonymous in the analysis.

- Thank you for completing this form

- The form should be submitted via Qualtrics by (DD/MM/YY)

1. Are you aware if the approach to teaching research methods at your institution has been reviewed in the past three years?

2. Does meeting the programme objectives require students to understand research methods to complete assessed course work and projects.?

1. Is the approach to teaching research methods predominantly classroom based?

2. Is the approach to teaching research methods predominantly on-line?

3. Is the approach to teaching research methods predominantly blended learning?

4. Is the proportion of individually assessed work as opposed to group work relating to research methods appropriate?

Free format text box

1. Briefly outline how, what and when research methods are taught.

2. If on-line material is provided as part of the course - what platform is in use e.g. Moodle, Canvas, or some other virtual learning environment?

RQ2 How does an understanding of research methods contribute to the curriculum?

1. Does academic writing, critical thinking and analysis require an understanding of research methods?

2. Is an understanding of research methods applicable at both undergraduate and postgraduate levels? 
1. Would students expect there to be benefits post course completion from an appreciation of research methods e.g. career benefits?

2. Does the course have a prescribed or preferred approach to research method e.g. action research, qualitative or quantitative methods?

3. Is an understanding of research skills regarded as an essential set of skills / competences?

4. Is there a course assessment for knowledge of and application of research methods? E.g. A project or dissertation.

5. Do students have the opportunity to choose between a number of different types of projects e.g. literature review, consultancy exercise, empirical research etc.?

\section{Free format text box}

1. Are you aware of future changes planned for the teaching of research methods and/or their application to course work and projects? If so, describe briefly.

1. Are students briefed or given guidelines on 'how to work with their supervisor'?

2. If either party feels that the process is not working satisfactorily is there a senior faculty member that students can refer to?

1. Do supervisors follow a prescribed approach?

2. Are students able to influence the choice or request a supervisor?

3. Do students work with their supervisor on a 1:1 basis?

4. Is group supervision available?

5. Is there a process for consulting experts other than a student's designated supervisor?

6. If a project is being carried out in conjunction with an employer, does the employer take an interest in supervision?

7. Do you agree that your supervisor has been able to guide or further assist you in the understanding and choice of research methods?

\section{Free format text box}

1. With what frequency are students and supervisors encouraged to meet?

2. Is it important that written as well as verbal feedback is given to the student?

3. How do you think that the supervision process can be improved?

Thank you for completing the questionnaire

Prof. Anthony Mitchell

Please return via Qualtrics

\section{Dr. Martin Rich}

by date $\gg \gg \gg \gg \gg \gg \gg \gg$ 